\title{
Interfacial adhesion of zirconia/veneer bilayers with different thermal characteristics
}

\author{
Nadine FREIFRAU VON MALTZAHN ${ }^{1}$, Martin KLEIBE ${ }^{1}$, Meike STIESCH${ }^{1}$, Christoph HÜBSCH${ }^{2}$ \\ and Philipp KOHORST ${ }^{1,3}$ \\ ${ }^{1}$ Department of Prosthetic Dentistry and Biomedical Materials Science, Hannover Medical School, Carl-Neuberg-Str. 1, 30625 Hannover, Germany \\ ${ }^{2}$ Institute for Materials Science, Leibniz University Hannover, An der Universität 2, 30823 Garbsen, Germany \\ ${ }^{3}$ Department of Prosthetic Dentistry and Biomaterials, Saarland University Medical Center, Kirrberger Str. 100, 66424 Homburg, Germany \\ Corresponding author, Philipp KOHORST; E-mail: kohorst.philipp@mh-hannover.de
}

\begin{abstract}
The aim of this study was to investigate how changes in the thermal characteristics of veneer ceramics with almost identical chemical and mechanical properties but with different coefficients of thermal expansion (CTE) can modify their interfacial adhesion to zirconia. 48 bilayers made of one Y-TZP ceramic and four veneer ceramics were fabricated $(n=12)$. Thermal residual stresses were calculated on the basis of the CTE and glass transition temperatures. After defined notching all specimens were loaded in a four-point bending test and the critical loads were recorded which induced stable crack extension at the adhesion interface. The strain energy release rate $\left(G, \mathrm{~J} / \mathrm{m}^{2}\right)$ was calculated and was taken as a measure of interfacial adhesion. The CTE of the veneer ceramics were significantly correlated with their adhesion to Y-TZP $(p<0.001)$. Interfacial adhesion in zirconia/veneer bilayers is predominantly affected by the thermal characteristics of the veneer ceramic.
\end{abstract}

Keywords: Zirconia, Veneer ceramic, Bond strength, Residual stresses, Strain energy release rate

\section{INTRODUCTION}

Modern metal-free prostheses provide high biocompatibility and good aesthetics and play a major role in modern dentistry. In this context, the high-strength ceramic zirconia is particularly useful in the fabrication of dental restorations. These prostheses can be machined and contoured fully anatomically, or produced as bilayer restorations compounded of a zirconia core veneered with a glass-ceramic material. Although zirconia is regarded as a high performance dental ceramic with many advantages and possible indications, the zirconia/veneer interface is known to be critical. Under functional loading, fractures may develop from the veneer layer or within the zirconia/ veneer interfacial area, resulting in clinic failure of the restorations ${ }^{1,2)}$. The incidence of these complications is higher than with traditional metal-ceramic restorations ${ }^{3}$. However, two types of fracture have to be differentiated. On the one hand, there may be cohesive fractures of the veneer ceramic; this is called "chipping" and has been reported to occur in up to $25 \%$ of zirconiabased restorations ${ }^{2,4-6)}$. On the other hand, there may be adhesive fractures between the core and the veneer ceramic, which is known as "delamination"7,8). Residual thermal stresses between the veneer and the core ceramic are deemed to be one of the major reasons for these clinical failures of zirconia-based restorations ${ }^{9-12)}$. These stresses are governed by the mismatch between the coefficients of thermal expansion (CTE) of the core and the veneer, the cooling rate after the sintering

Color figures can be viewed in the online issue, which is available at J-STAGE.

Received Jul 3, 2013: Accepted Feb 13, 2014

doi:10.4012/dmj.2013-181 JOI JST.JSTAGE/dmj/2013-181 process, viscoelastic effects in the range of the glass transition temperature and the composition of the core and veneer ceramics ${ }^{13)}$. Göstemeyer et al. confirmed some of these theoretical aspects in an in-vitro study, by evaluating the influence of CTE and cooling rate, using a sensitive measurement method (strain energy release rate ${ }^{14,15)}$. Fischer et al. reported similar results with conventional bond strength tests ${ }^{10,11}$. However, all these studies investigated zirconia/veneer combinations which not only showed differences in the CTE mismatch but also employed veneer ceramics of different chemical compositions. These differences in chemical composition may significantly influence interfacial adhesion in zirconia/veneer bilayer systems. Although Dündar et al. have reported that chemical composition may influence bond strength in combinations of glass ceramics or alumina ceramics and the corresponding veneer ceramics ${ }^{16)}$, there has not, to our knowledge, been any comparable study with zirconia/veneer specimens.

The aim of the present study was to investigate how differences in the thermal characteristics of veneer ceramics modify the interfacial adhesion of zirconia/veneer bilayers. As a specific feature of this investigation, veneer ceramics with almost identical chemical compositions and mechanical characteristics were used. It was hypothesized that the CTEs of these chemically identical veneer ceramics would have a significant influence on interfacial adhesion to zirconia.

\section{MATERIALS AND METHODS}

Materials

The present study was performed with combinations of 
a single yttria-stabilised tetragonal zirconia polycrystal (Y-TZP, Z 700, BCE Special Ceramics, Mannheim, Germany) core ceramic and four different leucite-free veneering ceramics (Dentaurum, Ispringen, Germany). The experimental veneering ceramics (VC_1-VC_4) were provided by a single manufacturer and had an almost identical chemical composition. However, the coefficients of thermal expansion of the veneer ceramics varied between $8.6 \mathrm{ppm} \mathrm{K} \mathrm{K}^{-1}$ and $9.4 \mathrm{ppm} \mathrm{K}^{-1}$. Detailed data about the thermal and mechanical characteristics of the ceramics used are given in Table 1 .

\section{Chemical composition analysis of veneer ceramics}

The element composition of finally sintered veneer ceramic specimens (VC_1-VC_4) was determined by means of energy dispersive X-ray spectroscopy (EDS), with a Si-detector (Bruker, Karlsruhe, Germany) which was connected to a scanning electron microscope (LEO 1455VP, Zeiss, Oberkochen, Germany). A high voltage of $20 \mathrm{kV}$ was used for the elemental analysis. Single spots of certain phases were measured.

Additionally, X-ray diffraction (XRD) measurements were performed with the diffractometer X'Pert MPD (Philips, Almelo, The Netherlands) in the range of 5-90 $2 \theta$ with a scanning speed of $0.03 \%$. A high voltage of 40 $\mathrm{kV}$ and a current of $40 \mathrm{~mA}$ were used.

\section{Calculation of thermal residual stresses}

Thermal expansion coefficients $(\alpha)$ in the interval 20$500^{\circ} \mathrm{C}$ and the glass transition temperatures $\left(T_{g}\right)$ of the different ceramics were given by the manufacturers (Table 1). Thermal and mechanical analysis of the batches of the investigated materials was performed in advance by the manufactures according to ISO $6872^{17)}$. Based on these data, the thermal residual stresses $\left(\sigma_{R}\right)$ for all four material combinations were calculated. Thermal residual stresses are developed by differences in the thermal expansion properties of core and veneer between the glass transition temperature and room temperature. These were calculated for each core/veneer composition by the following equation ${ }^{18)}$ :

$$
\sigma_{R}=\frac{\Delta \alpha \cdot \Delta T}{\left[\frac{\left(1+v_{C}\right)}{2 \mathrm{E}_{C}}+\left(1-2 v_{V}\right) \cdot \mathrm{E}_{V}\right]}
$$

where $\Delta \alpha$ is the difference between the CTEs of the core and the veneering ceramic $\left(\alpha_{\text {core }}-\alpha_{\text {veneer }}\right)$ and $\Delta T$ is the difference between the glass transition temperature of the veneering ceramic and room temperature $\left(T_{g} 20^{\circ} \mathrm{C}\right)$. $v$ and $E$ are the Poisson's ratio and the elastic modulus of the core (subscript $C$ ) and the veneer (subscript $V$ ), respectively. General values for $v$ and $E$ were obtained from the literature (Table 1$)^{13,19)}$.

\section{Determination of the strain energy release rate}

Bilayer core/veneer specimens were fabricated to measure the strain energy release rate $\left(G, \mathrm{~J} / \mathrm{m}^{2}\right)$ in a four-point bending test. The strain energy release rate during stable crack growth at the bonding interface was used as a measure of the bond strength of the ceramic composites.

A total of 48 rectangular zirconia specimens with dimensions of $25 \mathrm{~mm}$ in length, $8 \mathrm{~mm}$ in width and 1.25 $\mathrm{mm}$ in thickness were provided by the manufacturer and divided into the four test groups $(n=12)$. These zirconia specimens had been processed by the manufacturer in a pre-sintered state and had afterwards been sintered to their final dimensions. During this processing no HIP (Hot Isostatic Pressing) had been performed. The quality of the as sintered surfaces was assessed by profilometry as the arithmetic mean roughness $\left(R_{a}\right)$, with the following parameters: radius of stylus point curvature $2.5 \mu \mathrm{m}$, evaluation length $4 \mathrm{~mm}$, cut-off wavelength 0.8 $\mathrm{mm}$. Measurements were performed on five different locations per specimen (Dektak 150, Veeco Instruments, Tucson/Arizona, USA). Profilometry showed an identical average $R_{a}$ of $0.27 \mu \mathrm{m}$ for all surface sides of the Y-TZP specimens.

In the next step, zirconia specimens were cleaned up with absorbent cotton, impregnated with 99\% ethanol, and placed into a separable steel mould, in which $1.75 \mathrm{~mm}$ clearance was available for the veneer

Table 1 Data for residual stresses $\left(\sigma_{R}\right)$ between core and veneer ceramic calculated from thermal expansion coefficients between $20^{\circ} \mathrm{C}$ and $500{ }^{\circ} \mathrm{C}(\alpha)$, glass transition temperatures $\left(T_{g}\right)$, Poisson's ratios and elastic moduli of the materials. To characterize the used ceramics, flexural strength and fracture toughness values are also given (SD: standard deviation)

\begin{tabular}{|c|c|c|c|c|c|c|c|}
\hline Material & $\begin{array}{l}\text { Poissons's } \\
\text { ratio }\end{array}$ & $\begin{array}{c}\text { Elastic } \\
\text { modulus }(\mathrm{GPa})\end{array}$ & $\begin{array}{c}T_{g}\left({ }^{\circ} \mathrm{C}\right) \\
\text { mean }(\mathrm{SD})\end{array}$ & $\begin{array}{c}\alpha\left(\mathrm{ppm} \mathrm{K} \mathrm{K}^{-1}\right) \\
\operatorname{mean}(\mathrm{SD})\end{array}$ & $\sigma_{R}(\mathrm{MPa})$ & $\begin{array}{c}\text { Flexural } \\
\text { strength }(\mathrm{MPa}) \\
\text { mean }(\mathrm{SD})\end{array}$ & $\begin{array}{c}\text { Fracture } \\
\text { toughness } \\
\mathrm{K}_{\mathrm{IC}}\left(\mathrm{MPa} \mathrm{m}^{1 / 2}\right)\end{array}$ \\
\hline Y-TZP & 0.32 & 200 & - & $10.6(0.1)$ & - & 1000 & 10.50 \\
\hline VC_1 & 0.20 & 70 & $544.2(1.8)$ & $8.6(0.1)$ & -25.0 & $123(16)$ & 0.75 \\
\hline VC_2 & 0.20 & 70 & $537.8(2.4)$ & $9.0(0.1)$ & -19.7 & $129(20)$ & 0.75 \\
\hline VC_3 & 0.20 & 70 & $529.4(2.1)$ & $9.2(0.1)$ & -17.0 & $120(15)$ & 0.75 \\
\hline VC_4 & 0.20 & 70 & $533.7(1.7)$ & $9.4(0.1)$ & -14.7 & $132(21)$ & 0.75 \\
\hline
\end{tabular}


layer (own construction, Hannover Medical School, Hannover, Germany). An additional heat treatment of the zirconia specimens prior to the veneering process was not performed. Then different veneering ceramic powders were mixed with one and the same universal mixing liquid (LV, Dentaurum, Ispringen, Germany), poured into the mould and condensed. Excess mixing liquid was eliminated by applying tissue paper onto the surface of the veneer. After the mould had been removed, the specimens were positioned on a firing tray, placed in a ceramic furnace (Multimat MC II, De Trey Dentsply, Konstanz, Germany) and sintered with the first dentin firing cycle (Table 2). As a result of sintering shrinkage, the zirconia plates were not fully covered with the veneer layer after this first sintering process. For this reason, the specimens were returned to the mould, a second layer of the veneering material was laid on and sintering was repeated in the second dentin firing cycle (Table 2).

Subsequently, excess veneering material on the edges of the specimens was ground off and the veneering surface of the specimens was ground flat in a rotary polishing machine (Variable Speed Grinder/Polisher Power Pro 4000, Buehler LTD, Lake Bluff, USA) with a $45 \mu \mathrm{m}$ diamond abrasive wheel, until the total specimen thickness was $2.5 \mathrm{~mm}$ (1.25 $\mathrm{mm}$ core+1.25 mm veneer). The quality of the grinded veneer surfaces was assessed by profilometry as already described above for the Y-TZP ceramics. An average $R_{a}$ of $0.46 \mu \mathrm{m}$ was determined for the veneer ceramic surfaces. After this finishing process, all bilayered specimens were notched using the singleedge V-notched-beam (SEVNB) method, as described in ISO $23146^{20)}$. In the middle of the veneering ceramic side, a $0.2 \mathrm{~mm}$ deep pre-notch was made using a 0.2 $\mathrm{mm}$ thick rotary diamond cutting blade (ISOMet 4000, Buehler LTD) with lubricant (Isocut Plus cutting fluid,

Table 2 Firing schedules according to the manufacturer's instructions for the first and second dentin firing cycle (vacuum during heating)

\section{Firing schedules}

$$
\begin{aligned}
& \text { Pre-drying (no vacuum) } \\
& \text {-Temperature }\left({ }^{\circ} \mathrm{C}\right) \\
& \text {-Time (min) }
\end{aligned}
$$

Pre-heating (min)

Heating rate $\left({ }^{\circ} \mathrm{C} / \mathrm{min}\right)$

Firing temperature $\left({ }^{\circ} \mathrm{C}\right)$ -1 . Dentin Firing -2. Dentin Firing

Holding time (min) -1. Dentin Firing -2. Dentin Firing

Vacuum (min)

Vacuum (hPa)
Buehler Ltd). This notch was manually extended with a razor blade with $6 \mu \mathrm{m}$ diamond paste until the $\mathrm{V}$-shaped notch was $0.5 \mathrm{~mm}$ deep.

All specimens were tested in a four-point bending jig, according to DIN EN 84321) (own construction, Institute of Materials Science, Leibniz University Hannover, Garbsen, Germany), with the specimens mounted in a universal testing machine (Z2010, Zwick, Ulm, Germany). The distance between the inner loading rollers on the core side was $10 \mathrm{~mm}$ and between the outer support rollers on the veneering side $20 \mathrm{~mm}$. All bilayer specimens were placed in the jig with the veneering ceramic on the side of tensile stresses and continuously loaded on the core ceramic side at a crosshead speed of $0.01 \mathrm{~mm} / \mathrm{min}$ (Fig. 1), while data for cross-head displacement and load were collected and crack growth in the specimens was visually inspected. The strain energy release rate was calculated for the mean loading data, recorded in a plateau region of the load/cross-head displacement curves where stable crack growth at the bonding interface could be observed (Fig. 2 ), and using the following equation ${ }^{22)}$ :

$$
G=\frac{\eta\left(F^{2} l^{2}\right)\left(1-v_{C}^{2}\right)}{E_{C} b^{2} h^{3}}
$$

where $F$ is the mean load at the plateau region, 1 the distance between the inner and outer rollers, $b$ the width and $h$ the height of the test specimens. $v_{C}$ and $E_{C}$ are Poission's ratio and elastic modulus of the zirconia core, respectively. The parameter $\eta$ includes all geometrical parameters of the specimens and is calculated from:

$$
\eta=\left(\frac{3}{2}\right)\left[\frac{1}{\left(\frac{h_{C}}{h}\right)^{3}}-\frac{\lambda}{\left\{\left(\frac{h_{V}}{h}\right)^{3}+\lambda\left(\frac{h_{C}}{h}\right)^{3}+3 \lambda\left(\frac{h_{V} h_{C}}{h^{2}}\right)\left(\frac{h_{V}}{h}-\frac{\lambda h_{C}}{h}\right)^{-1}\right\}}\right]
$$

with:

$$
\lambda=\frac{E_{C}\left(1-v_{V}^{2}\right)}{E_{V}\left(1-v_{C}^{2}\right)}
$$

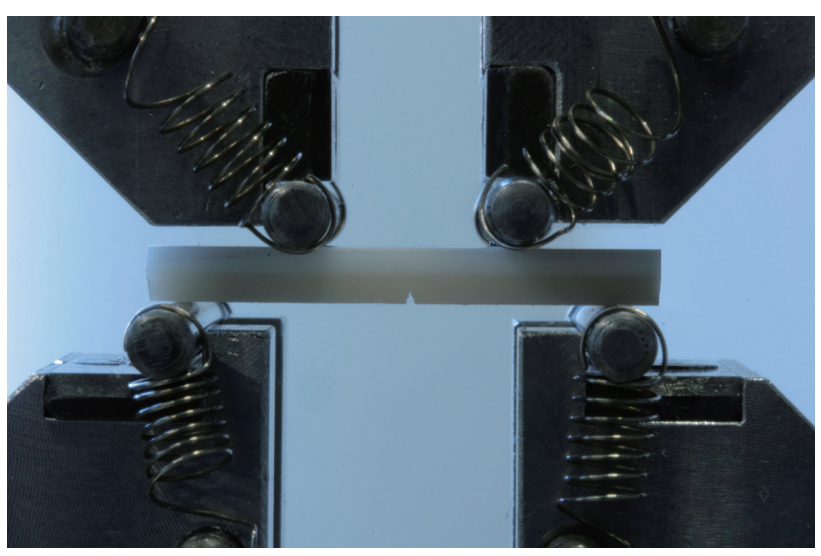

Fig. 1 Image of the four-point bending configuration with a pre-notched specimen. 


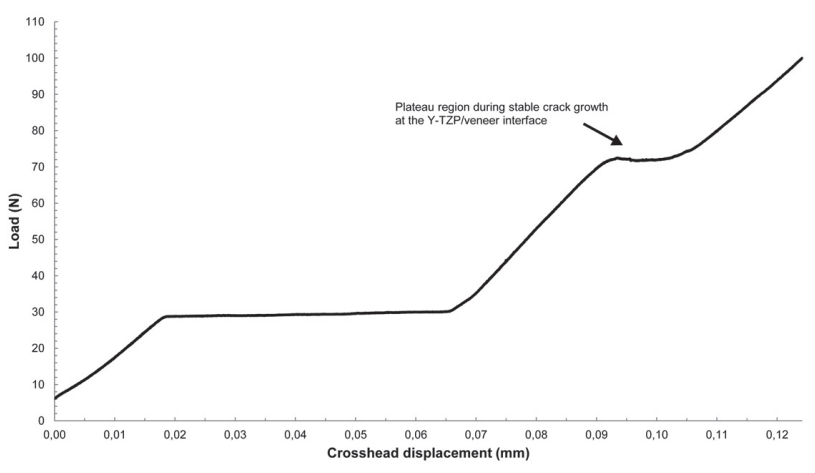

Fig. 2 Typical load/crosshead displacement curve of the four-point bending test configuration.

The non-elastic behaviour of the curve between 0.015 and $0.065 \mathrm{~mm}$ was caused by a displacement of the moving parts of the four-point bending jig.

where $h_{C}$ and $h_{V}$ are the thickness of core and veneer and $v_{V}$ and $E_{v}$ are the Poisson's ratio and the elastic modulus of the veneer, respectively. Values for $v$ and $E$ used are shown in Table 1.

\section{SEM analysis}

This analysis was used to follow crack development. One test specimen of each group was attached in conductive resin (Epo Thin, Buehler, Lake Bluff, IL) and cut at right angles to the prepared notch and the core/veneering interface using a diamond cutting blade (IsoMet 4000, Buehler LTD) with lubricant (Isocut Plus cutting fluid, Buehler LTD). In the last finishing step, the cut surfaces of the specimens were buffed in a rotary polishing machine (Variable Speed Grinder/Polisher Power Pro 4000, Buehler LTD), with $1 \mu \mathrm{m}$ diamond abrasive fluid. No further preparation of the test specimens was necessary for the analysis of the fracture surface. SEM analysis was performed on the LEO 1455VP device (Zeiss, Oberkochen, Germany).

\section{Statistical analysis}

Statistical analysis was performed using SPSS for Windows, version 19.0 (IBM, Ehringen, Germany). The normal distribution of data and homogeneity of variance were checked using the Kolmogorov-Smirnov and Levene tests, respectively. The influence of the thermal expansion coefficient on strain energy release rate was checked by one-way analysis of variance (ANOVA), with the level of significance set at 0.05. Differences between individual groups were checked for significance with the post-hoc Tamhane test.

\section{RESULTS}

Detailed data regarding element composition of the veneer ceramics at different measuring points (see SEM images/Figs. 3-6) is given in Table 3. Comparison of the element analyses revealed that the composition of the various veneer ceramics were in a very similar range at the certain measuring points.

XRD measurements showed the amorphous character of the samples. No distinct peaks were determined, only a characteristic broad peak has been found in the range between $15-40^{\circ} 2 \theta$ where the highest intensities for silica usually appear.

Thermal residual stresses occurring in the veneering layer of the bilayer specimens were calculated from the data given by the manufacturers and ranged between -25.0 MPa (VC_1) and -14.7 MPa (VC_4) (Table 1).

In all specimens, stable crack growth was observed during determination of the strain energy release rate by a four-point bending test. Every load-displacement curve recorded for each specimen showed a distinct plateau region (Fig. 2), correlating to stable crack growth at the core/veneer interface, and strain energy release rate $(G)$ could be calculated. $G$-values ranged from $4.7 \pm 1.1 \mathrm{~J} / \mathrm{m}^{2}$ (VC_4) to $10.2 \pm 2.2 \mathrm{~J} / \mathrm{m}^{2}$ (VC_1) and statistical analysis showed significant differences for the different core/ veneer compositions (ANOVA, $p<0.001$ ). Detailed data are shown in Table 4 and Fig. 7. The correlation between $G$-values and thermal residual stresses revealed that the material combination with the highest compressive stresses (VC_1) showed the highest interfacial adhesion, and correspondingly the lowest $G$-values were found for the core/veneer combination which exhibited the lowest compressive stresses (VC_4).

SEM analysis demonstrated that, during loading, the crack was initiated at the pre-notch, ran through the veneer ceramic, bifurcated near the core/veneer interface and propagated at the core/veneer interface until it stopped in the area of the inner rollers (Fig. 8). The fracture surface exhibited a mixed fracture pattern; this was identical in all investigated material compositions (Figs. 9 and 10). An ultra-thin residual layer of the veneer ceramic was left on the zirconia surface. However, the veneer layer was totally delaminated in some areas and the zirconia surface was exposed. These delaminated areas probably occurred due to small pores which had been incorporated during the build-up of the veneer layer on the zirconia surface.

\section{DISCUSSION}

Adhesion between the core and the veneer ceramic is known to be one of the most crucial aspects influencing the long-term clinical results of all-ceramic restorations. The clinical success of zirconia-based restorations is significantly limited by chipping or delamination of the veneer ceramic ${ }^{8,23,24)}$. Various test set-ups have been used to determine the adhesion between core and veneer: for example, shear tests, flexure tests, tensile tests and interfacial fracture tests ${ }^{11,16,18,25,26)}$. However, most of these tests do not provide reliable evidence for adhesion, as they cannot assure separation between core and veneer ceramic within the adhesion surface. Flexure, traction and shear tests often show cohesive fracture patterns and cannot ensure uniform stress distribution at the core/veneer interface during load application, resulting in considerable scatter in the values of bond 


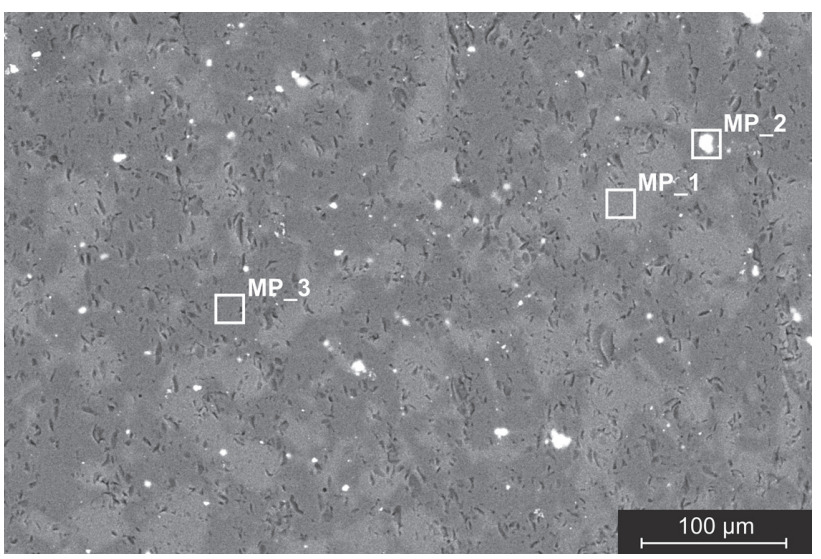

Fig. 3 SEM image of the microstructure of the densely sintered veneer ceramic VC_1.

Characteristic measuring points (MP_1-MP_3) used for element analysis (EDS) are displayed.

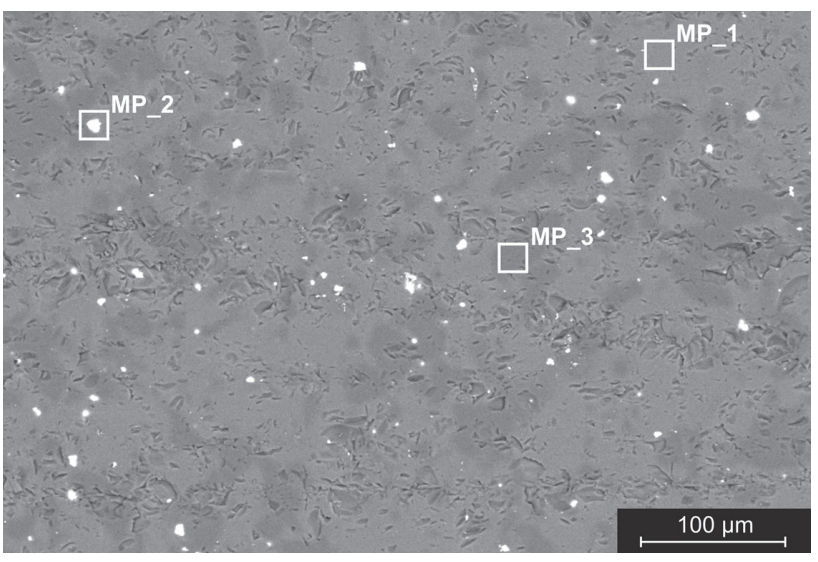

Fig. 4 SEM image of the microstructure of the densely sintered veneer ceramic VC_2.

Characteristic measuring points (MP_1-MP_3) used for element analysis (EDS) are displayed.

strengths measured ${ }^{27,28)}$. An alternative method based on a fracture mechanics approach (strain energy release rate), first described by Charalambides et al. ${ }^{22)}$, was used in the present survey to evaluate adhesion between zirconia core and veneer ceramic. This test design has the advantage of eliminating non-uniform stress distribution during the testing procedure and ensures stable crack growth at the adhesion interface. Furthermore, the layer thickness of core and veneer ceramics was more similar to the core/veneer dimensions of clinically used restorations than in other test methods. This may be important, as stress distribution at a bilayer interface is significantly affected by the layer thickness of the components ${ }^{13,29)}$.

Recently, strain energy release rate has been evaluated with zirconia core and veneer ceramics and has been found to be a reliable method for analysing

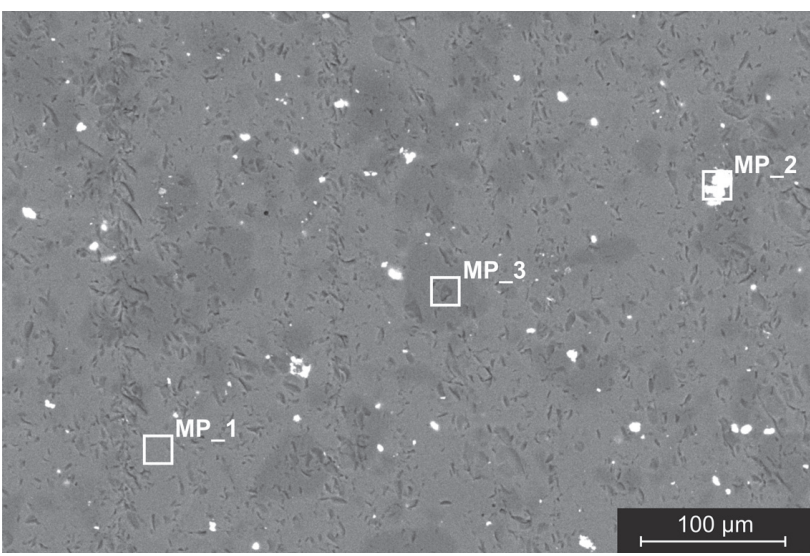

Fig. 5 SEM image of the microstructure of the densely sintered veneer ceramic VC_3.

Characteristic measuring points (MP_1-MP_3) used for element analysis (EDS) are displayed.

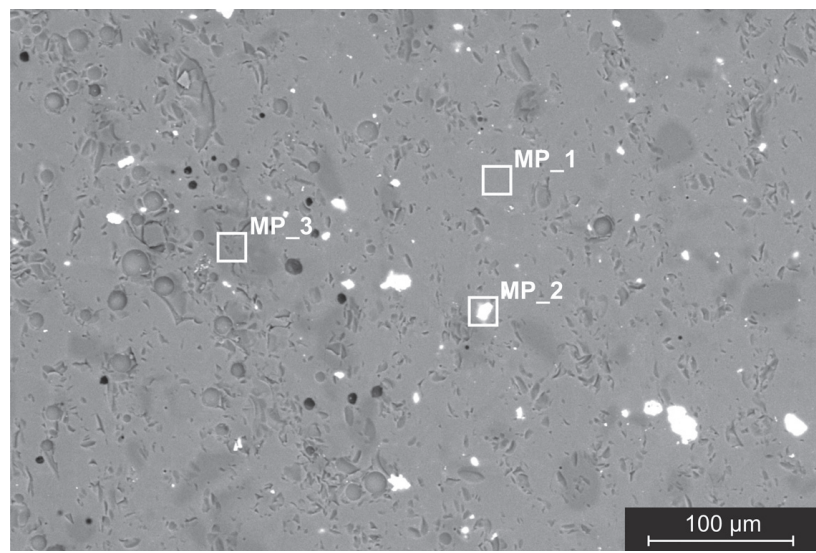

Fig. 6 SEM image of the microstructure of the densely sintered veneer ceramic VC_4.

Characteristic measuring points (MP_1-MP_3) used for element analysis (EDS) are displayed.

interfacial adhesion ${ }^{14,15)}$. These studies revealed that interfacial adhesion between the materials is significantly influenced by residual stresses, which are themselves affected by the thermal characteristics of the components. In this context, slight compressive stresses of about $-20 \mathrm{MPa}$ (correlating to a CTE mismatch of $\approx 1.4$ ppm $\mathrm{K}^{-1}$ ) in the adhesion zone have been reported to be beneficial for zirconia/veneer interfacial adhesion ${ }^{14)}$. Beside the thermal characteristics of these materials, these stresses could also be influenced by modulating the cooling rate within the firing process ${ }^{15}$.

However, one serious criticism of these studies is that the investigated veneer ceramics (which were provided by various manufacturers) not only differed in their thermal characteristics, but also in their chemical compositions. Beside the CTE mismatch of the bilayer components, these variations in the 
Table 3 Results of elemental analysis (EDS) for the different veneer ceramics. For each material EDS was performed at characteristic measuring points (MP_1-MP_3) which are denoted on the SEM pictures of the respective ceramic (Figs. 3-6)

\begin{tabular}{|c|c|c|c|c|c|c|c|c|c|c|c|}
\hline \multirow{2}{*}{ Material } & \multirow{2}{*}{$\begin{array}{l}\text { Measuring } \\
\text { point }\end{array}$} & \multicolumn{10}{|c|}{ Elemental composition in wt\% } \\
\hline & & $\mathrm{C}$ & $\mathrm{O}$ & $\mathrm{Na}$ & $\mathrm{Al}$ & $\mathrm{Si}$ & $\mathrm{K}$ & $\mathrm{Ca}$ & $\mathrm{Zr}$ & $\mathrm{Ba}$ & Hf \\
\hline \multirow{3}{*}{$\begin{array}{l}\text { VC_1 } \\
\text { Fig. } 3\end{array}$} & MP_1 & 0.0 & 37.8 & 9.4 & 7.7 & 32.0 & 4.8 & 2.0 & 0.0 & 6.4 & 0.0 \\
\hline & MP_2 & 0.2 & 25.9 & 2.1 & 1.4 & 7.6 & 1.8 & 0.5 & 57.9 & 1.8 & 0.8 \\
\hline & MP_3 & 0.0 & 39.7 & 8.1 & 6.2 & 34.3 & 5.1 & 1.6 & 0.0 & 5.0 & 0.0 \\
\hline \multirow{3}{*}{$\begin{array}{l}\text { VC_2 } \\
\text { Fig. } 4\end{array}$} & MP_1 & 0.0 & 37.2 & 9.2 & 7.8 & 32.1 & 5.3 & 2.0 & 0.0 & 6.4 & 0.0 \\
\hline & MP_2 & 2.0 & 26.4 & 3.8 & 2.6 & 11.1 & 2.1 & 0.8 & 48.5 & 2.1 & 0.7 \\
\hline & MP_3 & 0.0 & 39.1 & 8.0 & 6.4 & 34.2 & 5.8 & 1.5 & 0.0 & 5.0 & 0.0 \\
\hline \multirow{3}{*}{$\begin{array}{l}\text { VC_3 } \\
\text { Fig. } 5\end{array}$} & MP_1 & 0.0 & 39.2 & 7.9 & 5.9 & 33.8 & 6.2 & 1.7 & 0.0 & 5.3 & 0.0 \\
\hline & MP_2 & 0.7 & 24.2 & 1.9 & 1.3 & 5.6 & 1.8 & 0.6 & 61.2 & 1.9 & 0.8 \\
\hline & MP_3 & 0.0 & 27.6 & 8.5 & 6.9 & 42.1 & 7.0 & 1.9 & 0.0 & 6.1 & 0.0 \\
\hline \multirow{3}{*}{$\begin{array}{l}\text { VC_4 } \\
\text { Fig. } 6\end{array}$} & MP_1 & 0.0 & 37.3 & 9.4 & 7.9 & 31.1 & 5.8 & 2.0 & 0.0 & 6.4 & 0.0 \\
\hline & MP_2 & 0.5 & 32.4 & 5.1 & 3.6 & 13.6 & 2.7 & 1.1 & 37.4 & 3.4 & 0.0 \\
\hline & MP_3 & 0.0 & 38.5 & 7.0 & 6.5 & 35.0 & 6.2 & 1.5 & 0.0 & 5.1 & 0.0 \\
\hline
\end{tabular}

Table 4 Strain energy release rates $(G)$ of bilayer specimens with different zirconia core/veneer combinations. Values denoted by the same superscript do not differ with statistical significance $(p<0.05)$

\begin{tabular}{|c|c|c|c|c|c|}
\hline \multicolumn{6}{|c|}{ Strain energy release rate, $G\left(\mathrm{~J} / \mathrm{m}^{2}\right)$} \\
\hline \multicolumn{2}{|c|}{ Material combinations } & \multirow{2}{*}{ Mean } & \multirow{2}{*}{$\begin{array}{l}\text { Standard } \\
\text { deviation }\end{array}$} & \multirow{2}{*}{ Minimum } & \multirow{2}{*}{ Maximum } \\
\hline Core & Veneer & & & & \\
\hline \multirow{4}{*}{ Y-TZP } & VC_1 & $10.2^{\mathrm{a}}$ & 2.2 & 6.5 & 12.9 \\
\hline & VC_2 & $6.6^{\mathrm{b}}$ & 1.8 & 4.5 & 11.4 \\
\hline & VC_3 & $5.0^{\mathrm{b}, \mathrm{c}}$ & 0.9 & 3.8 & 7.2 \\
\hline & VC_4 & $4.6^{\mathrm{c}}$ & 1.1 & 2.5 & 5.8 \\
\hline
\end{tabular}

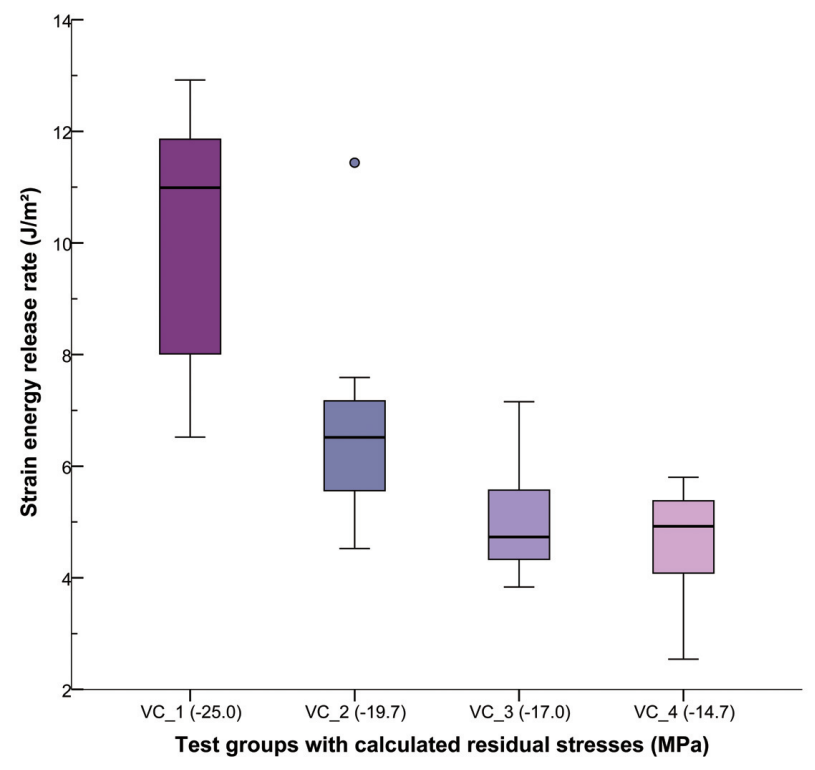

Fig. 7 Box chart representing the strain energy release rate of bilayer specimens with combination of zirconia core and different veneer ceramics. Medians, quartiles and extremes are given.

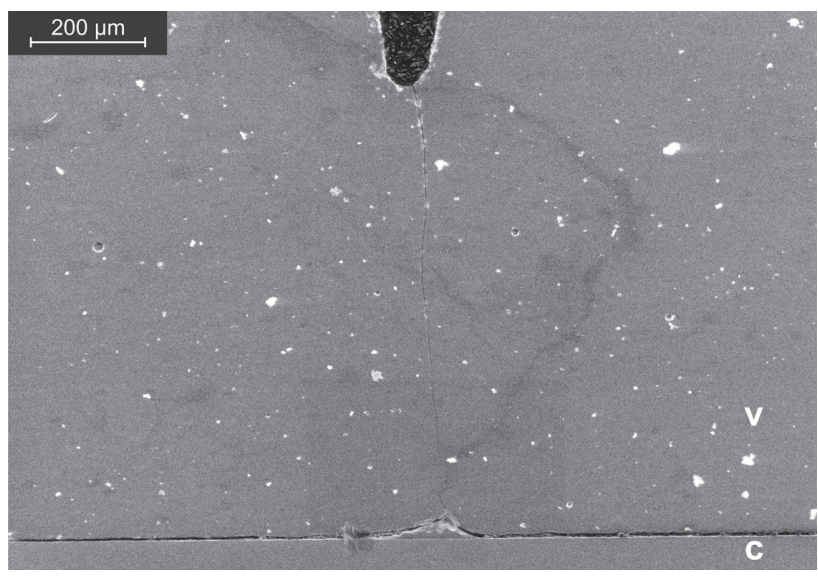

Fig. 8 Representative SEM image of the crack path of a tested core (c)/veneer (v) bilayer specimen. The crack started at the pre-notch, bifurcated near the core/veneer interface and propagated within the adhesive interface of the components. 


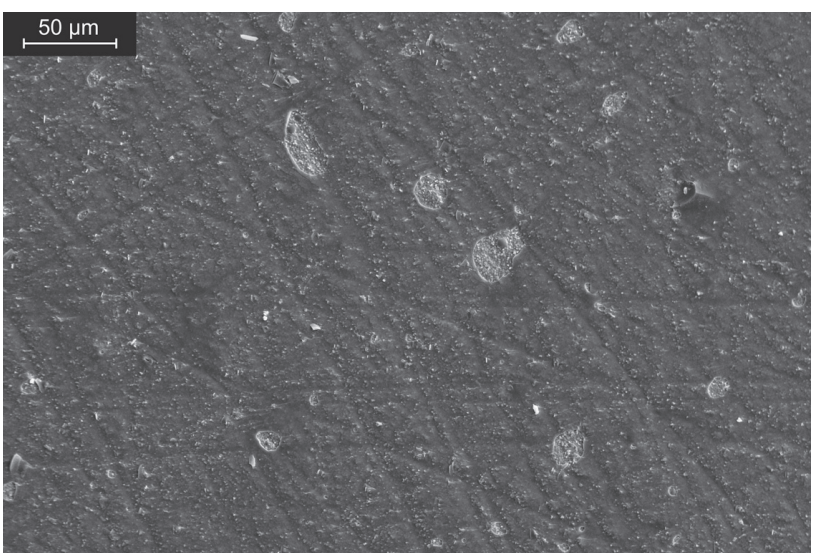

Fig. 9 SEM image of a typical fracture surface (250×magnification): the zirconia surface is almost completely covered by an ultra-thin layer of veneer ceramic.

chemical composition of the veneer ceramics may have significantly affected interfacial adhesion ${ }^{14,16}$. Therefore, in the present study, veneer ceramics with different thermal characteristics but almost identical chemical compositions and mechanical characteristics and from only one manufacturer were evaluated. This experimental protocol has never been reported before for adhesion testing of ceramic components.

Mean $G$-values in the present study differed with statistical significance and ranged between $4.6 \mathrm{~J} / \mathrm{m}^{2}$ (VC_4) and $10.2 \mathrm{~J} / \mathrm{m}^{2}$ (VC_1). The values were strongly correlated with the thermal residual stresses calculated for the different material combinations, with the highest interfacial adhesion at compressive stresses of about -25 $\mathrm{MPa}$ (VC_1), corresponding to a CTE mismatch of $\approx 2.0$ ppm $\mathrm{K}^{-1}$. Even though Göstemeyer et al. ${ }^{14,15)}$ reported similar results with an identical test set-up, they found the highest $G$-values for material combinations with calculated stresses of $-20 \mathrm{MPa}$. This might indicate that the chemical composition of the veneer ceramic influenced interfacial adhesion and has to be considered in the veneering recommendations. Chemical variations may not primarily affect direct bonding between the materials, but may influence e.g. the viscosity or the crystallization behavior of the ceramics, and thus structural and stress relaxation parameters. These phenomena particularly affect the material's thermal behavior above the glass transition temperature. For this temperature region, various studies have demonstrated significant changes in the thermal expansion properties which strongly affect thermal stress distribution ${ }^{30,31}$. However, the CTE values given by the manufacturer for the ceramic materials, and which has also been used for calculation of thermal residual stresses in the present and previous studies ${ }^{14,32,33)}$, only applies to the temperature range below the glass transition temperature $\left(20-500^{\circ} \mathrm{C}\right)$.

Nevertheless, the CTE mismatch between core and veneer ceramic is still the most important parameter

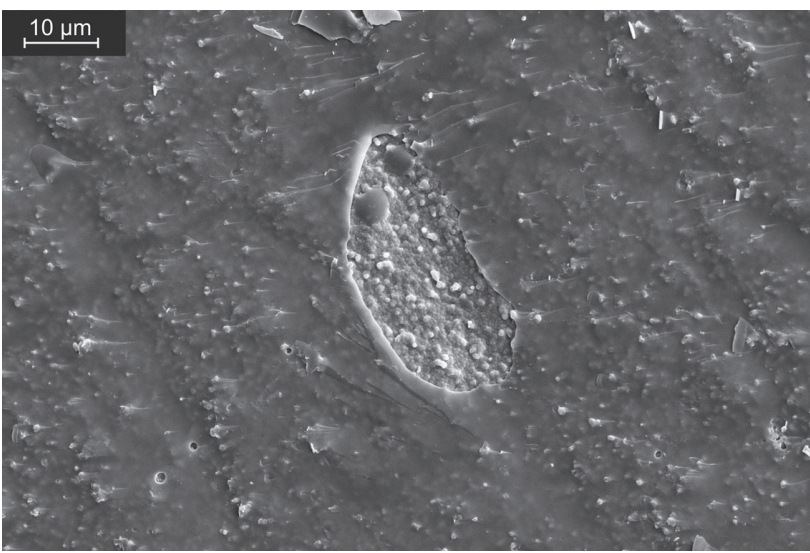

Fig. 10 Typical SEM image of the fracture surface (1,000×magnification) showing the exposure of the zirconia core material.

affecting the adhesion of the components; in this context, a CTE mismatch that leads to compressive stresses within the veneer layer is recommended. In this context, former studies, which also determined the strain energy release rate in zirconia core/veneer bilayers, reported highest interfacial adhesion for a CTE mismatch of about $1-2 \mathrm{ppm} \mathrm{K}^{-1}{ }^{14,15)}$. That mismatch corresponds to a CTE of the veneer ceramics between $8.6 \mathrm{ppm} \mathrm{K}^{-1}$ and $9.6 \mathrm{ppm} \mathrm{K}{ }^{-1}$. Veneer ceramics with a CTE more similar to that of zirconia $\left(10.6 \mathrm{ppm} \mathrm{K}^{-1}\right)$ showed lower bond strength and therefore ceramics with a coefficient of thermal expansion at this level had not been included in the present study. This view is also confirmed by several other studies which investigated zirconia core/ veneer interfacial adhesion using alternative test setups $^{10,11,34)}$. However, the present results show that no general recommendation can be made for an optimal CTE mismatch between the zirconia core and the veneer layer. Due to variations in the chemical composition of the veneer ceramics, other characteristics — such as viscosity or crystallization behavior - may vary and may have an additional effect on the interfacial adhesion of the components. Therefore, an individual CTE optimum has to be determined for each veneer ceramic.

\section{CONCLUSION}

Within the limitations of the current study it could be concluded that:

1. The thermal characteristics of the veneer ceramics significantly influence the interfacial adhesion of bilayer zirconia/veneer composites.

2. The mismatch in the coefficients of thermal expansion is the essential factor for the bond strength between veneer and zirconia core ceramics.

3. The chemical composition seems to be an additional co-factor influencing the thermal characteristics of the veneer ceramic. Therefore, 
determining an individual CTE optimum for every single ceramic may be appropriate to attain optimal interfacial adhesion in zirconia/veneer bilayers.

\section{ACKNOWLEDGMENTS}

This project was funded by the German Association for Prosthetic Dentistry and Biomaterials (DGPro). Material support for this study was given by Dentaurum (Ispringen, Germany), which is gratefully acknowledged. The article processing charge was funded by means of the DFG-project "Open Access Publishing" by the German Research Council.

\section{REFERENCES}

1) Schmitter M, Mussotter K, Rammelsberg $P$, Gabbert $O$, Ohlmann B. Clinical performance of long-span zirconia frameworks for fixed dental prostheses: 5-year results. J Oral Rehabil 2012; 39: 552-557.

2) Raigrodski AJ, Hillstead MB, Meng GK, Chung KH. Survival and complications of zirconia-based fixed dental prostheses: a systematic review. J Prosthet Dent 2012; 107: 170-177.

3) Rammelsberg P, Schwarz S, Schroeder C, Bermejo JL, Gabbert O. Short-term complications of implant-supported and combined tooth-implant-supported fixed dental prostheses. Clin Oral Implants Res 2012; doi:10.1111/j.16000501.2012.02482.x.

4) Vult von Steyern P, Carlson P, Nilner K. All-ceramic fixed partial dentures designed according to the DC-Zirkon technique. A 2-year clinical study. J Oral Rehabil 2005; 32: 180-187.

5) Sailer I, Pjetursson BE, Zwahlen M, Hämmerle CH. A systematic review of the survival and complication rates of all-ceramic and metal-ceramic reconstructions after an observation period of at least 3 years. Part II: Fixed dental prostheses. Clin Oral Implants Res 2007; 18 Suppl 3: 86-96.

6) Anusavice KJ. Standardizing failure, success, and survival decisions in clinical studies of ceramic and metal-ceramic fixed dental prostheses. Dent Mater 2012; 28: 102-111.

7) Al-Dohan HM, Yaman P, Dennison JB, Razzoog ME, Lang BR. Shear strength of core-veneer interface in bi-layered ceramics. J Prosthet Dent 2004; 91: 349-355.

8) Aboushelib MN, Feilzer AJ, Kleverlaan CJ. Bridging the gap between clinical failure and laboratory fracture strength tests using a fractographic approach. Dent Mater 2009; 25: 383-391.

9) Denry I, Kelly JR. State of the art of zirconia for dental applications. Dent Mater 2008; 24: 299-307.

10) Fischer J, Stawarczyk B, Trottmann A, Hämmerle CH. Impact of thermal properties of veneering ceramics on the fracture load of layered Ce-TZP/A nanocomposite frameworks. Dent Mater 2009; 25: 326-330.

11) Fischer J, Stawarzcyk B, Trottmann A, Hämmerle CH. Impact of thermal misfit on shear strength of veneering ceramic/zirconia composites. Dent Mater 2009; 25: 419-423.

12) DeHoff PH, Barrett AA, Lee RB, Anusavice KJ. Thermal compatibility of dental ceramic systems using cylindrical and spherical geometries. Dent Mater 2008; 24: 744-752.

13) Swain MV. Unstable cracking (chipping) of veneering porcelain on all-ceramic dental crowns and fixed partial dentures. Acta Biomater 2009; 5: 1668-1677.

14) Göstemeyer G, Jendras M, Borchers L, Bach FW, Stiesch M, Kohorst P. Effect of thermal expansion mismatch on the Y-TZP/veneer interfacial adhesion determined by strain energy release rate. J Prosthodont Res 2012; 56: 93-101.
15) Göstemeyer G, Jendras M, Dittmer MP, Bach FW, Stiesch M, Kohorst P. Influence of cooling rate on zirconia/veneer interfacial adhesion. Acta Biomater 2010; 6: 4532-4538.

16) Dündar M, Ozcan M, Gokce B, Comlekoglu E, Leite F, Valandro LF. Comparison of two bond strength testing methodologies for bilayered all-ceramics. Dent Mater 2007; 23: 630-636.

17) International Organisation of Standardisation. ISO 6872 - dentistry-ceramic materials. Geneva: International Organisation of Standardisation; 2008.

18) Taskonak B, Mecholsky JJ Jr, Anusavice KJ. Residual stresses in bilayer dental ceramics. Biomaterials 2005; 26: 3235-3241.

19) Suansuwan N, Swain MV. Determination of elastic properties of metal alloys and dental porcelain. J Oral Rehabil 2001; 28: 133-139.

20) International Organisation of Standardisation. ISO 23146 fine ceramics (advanced ceramics, advanced technical ceramics)-test methods for fracture toughness of monolithic ceramics-single-edge V-notch beam (SVENB) method. Geneva: International Organisation of Standardisation; 2008.

21) Deutsches Institut für Normung e.V. DIN EN 843Hochleistungskeramik. Berlin: Beuth Verlag; 2008.

22) Charalambides PG, Lund J, Evans AG, McMeeking RM A test specimen for determining the fracture resistance of bimaterial interfaces. J Appl Mech 1989; 56: 77-82.

23) Kelly JR, Tesk JA, Sorensen JA. Failure of all-ceramic fixed partial dentures in vitro and in vivo: analysis and modeling. J Dent Res 1995; 74: 1253-1258.

24) Thompson JY, Anusavice KJ, Naman A, Morris HF. Fracture surface characterization of clinically failed all-ceramic crowns. J Dent Res 1994; 73: 1824-1832.

25) Anusavice KJ, Kakar K, Ferree N. Which mechanical and physical testing methods are relevant for predicting the clinical performance of ceramic-based dental prostheses? Clin Oral Implants Res 2007; 18 Suppl 3: 218-231.

26) Guess PC, Kulis A, Witkowski S, Wolkewitz M, Zhang Y, Strub JR. Shear bond strengths between different zirconia cores and veneering ceramics and their susceptibility to thermocycling. Dent Mater 2008; 24: 1556-1567.

27) Suansuwan N, Swain MV. New approach for evaluating metal-porcelain interfacial bonding. Int J Prosthodont 1999; 12: 547-552.

28) Chung HG, Swain MV, Mori T. Evaluation of the strain energy release rate for the fracture of titanium-porcelain interfacial bonding. Biomaterials 1997; 18: 1553-1557.

29) Hsueh CH, Thompson GA, Jadaan OM, Wereszczak AA, Becher PF. Analyses of layer-thickness effects in bilayered dental ceramics subjected to thermal stresses and ring-onring tests. Dent Mater 2008; 24: 9-17.

30) DeHoff PH, Anusavice KJ, Vontivillu SB. Analysis of tempering stresses in metal-ceramic disks. J Dent Res 1996; 75: 743-751.

31) Asaoka K, Tesk JA. Visco-elastic deformation of dental porcelain and porcelain-metal compatibility. Dent Mater 1991; 7: 30-35.

32) Belli R, Petschelt A, Lohbauer U. Thermal-induced residual stresses affect the fractographic patterns of zirconia-veneer dental prostheses. J Mech Behav Biomed Mater 2013; 21: 167-177.

33) Tholey MJ, Swain MV, Thiel N. Thermal gradients and residual stresses in veneered Y-TZP frameworks. Dent Mater 2011; 27: 1102-1110.

34) Fischer J, Stawarczyk B, Tomic M, Strub JR, Hämmerle CH. Effect of thermal misfit between different veneering ceramics and zirconia frameworks on in vitro fracture load of single crowns. Dent Mater J 2007; 26: 766-772. 